nephritis without proteinuria (1.86 and 1.32). In three patients with low glomerular filtration rate (inulin clearance less than $10 \mathrm{ml} . / \mathrm{min}$.) we found ratios of from 1.44 up to 2.13 , in agreement with the findings of Miller et al. (1952). It is pertinent to note that in all these cases the ratio ${ }^{51} \mathrm{Cr}$ edetic acid clearance to inulin clearance remains close to 1.00 . Therefore ${ }^{51} \mathrm{Cr}$ edetic acid clearance gives a reliable estimate of inulin clearance even in the presence of proteinuria and advanced renal failure and in other renal diseases where creatinine clearance is unreliable.

$\mathrm{Cr}$ edetic acid is chemically inactive and has no chelating action. Downes and McDonald (1964), using large doses of $\mathrm{Cr}$ edetic acid in the rat, have shown that it does not cause renal damage. The total dose of ${ }^{51} \mathrm{Cr}$ edetic acid given for the purpose of measuring clearance in man is much lower than the dose administered when edetic acid is used as a chelating agent (5 mg. against $2-3,000 \mathrm{mg}$.). Ninety-eight per cent. of the $\mathrm{Cr}$ edetic acid administered is excreted through the kidney. Radiation dosage to the patient's kidney is comparatively trivial (Garnett et al., 1967). ${ }^{51} \mathrm{Cr}$ emits monochromatic gamma radiation of $320 \mathrm{keV}$ and is easily counted with any standard well-type scintillation counter. The ease of manufacture of ${ }^{81} \mathrm{Cr}$ edetic acid is an advantage over other labelled substances such as ${ }^{51} \mathrm{Cr}$ inulin (Johnson et al., 1967). The use of this substance is therefore safe and convenient.

\section{Summary}

Experiments in dogs have shown that the clearance of ${ }^{51} \mathrm{Cr}$ edetic acid remains identical with the simultaneous clearance of inulin, and that it is independent of the concentration of $\mathrm{Cr}$ edetic acid in the plasma. Simultaneous ${ }^{51} \mathrm{Cr}$ edetic acid, inulin, and endogenous creatinine clearances were measured in
20 patients with renal disease of various origin and a wide range of severity. The correlation between ${ }^{51} \mathrm{Cr}$ edetic acid and inulin clearances $(r=0.992)$ was found to be better than the correlation between creatinine and inulin clearances $(r=0.908) .{ }^{51} \mathrm{Cr}$ edetic acid is safe and convenient to use.

We thank Dr. R. F. Jewkes and Miss Barbara Jones, who carried out the isotope measurements ; Dr. Pierre Verroust for help with the dog experiments; Miss E. M. Clarkson in whose laboratory the creatinine estimations were performed; and $\mathrm{Mr}$. B. McAuliff for preparing the figures. We are especially grateful to $\mathrm{Mr}$. N. Veall, of Guy's Hospital, who made available the original supplies of ${ }^{51} \mathrm{Cr}$ edetic acid.

Supplies of ${ }^{51} \mathrm{Cr}$ edetic acid were obtained from Dr. D. J. Jenkins, Radiochemical Centre, Amersham, Buckinghamshire, England. A preservative in the form of $1 \%$ benzyl alcohol is now added, and in our hands results with this preparation have been identical with those obtained with solutions prepared without this preservative.

Requests for reprints should be addressed to A. J. Wing, Department of Medicine, Charing Cross Hospital Medical School, Fulham Hospital, Iondon W.6.

\section{REFERENCES}

Berlyne, G. M., Varley, H., Nilwarangkur, S., and Hoerni, M. (1964) Lancet, 2, 874 .

Breckenridge, A., and Metcaife-Gibson, A. (1965). Ibid., 2, 265.

Brit. med. F., 1967, 2, 458.

Downes, A. M., and McDonald, I. W. (1964). Brit. F. Nutr., 18, 153

Foley, T. H., Jones, N. F., and Clapham, W. F. (1966). Lancet, 2, 86

Führ, J., Kaczmarczyk, J., and Krüttgen, C.-D. (1955). Klin. W schr., 33, 729 .

Garnett, E. S., Parsons, V., and Veall, N. (1967). Lancet, 1, 818.

Johnson, A. E., Hartley, B., and Gollan, F. (1967). F. nucl. Med., 8, 97 Miller, B. F., Leaf, A., Mamby, A. R., and Miller, Z. (1952). F. clin. Invest., 31, 309.

Nelp, W. B., Wagner, H. N., jun., and Reba, R. C. (1964). F. Lab. clin Med., 63, 480 .

Stacy, B. D., and Thorburn, G. D. (1966). Science, 152, 1076

\title{
Treatment of Oral Lichen Planus with Betamethasone
}

\author{
R. A. CAWSON,* M.B., B.D.S., F.D.S. R.C.S., M.C.PATH.
}

Oral lichen planus is a relatively common form of stomatitis; it may be symptom-free, but soreness, sometimes severe, is typical of the erosive form. Soreness of the mouth for 10 years or more, with little in the way of remissions, is a particular characteristic of lichen planus, and demands effective treatment. There is also a suspicion that persistent oral lichen planus may be followed by malignant change, as described by Warin (1960) and others. Until recently the usual treatment was hydrocortisone (Corlan) pellets, which seem only occasionally to have any effect, and tetracycline mouth washes, which of ten seem to expedite healing of erosions.

Betamethasone 17-valerate (Betnovate) is a synthetic corticosteroid with much greater anti-inflammatory effect than cortisone and has been noted by Williams et al. (1964) to cause dermal lesions of lichen planus to regress. Betamethasone was prepared in $0.1-\mathrm{mg}$. pellets with the original purpose of comparing it with hydrocortisone pellets in a double-blind trial in the treatment of recurrent aphthous ulceration. This trial was extended to include lichen planus. Betamethasone pellets were also used in the treatment of oral lesions of mucous membrane pemphigoid as described below.

\footnotetext{
- Department of Oral Medicine and Pathology, Guy's Hospital Medical
} School, London S.E.1.

\section{Present Investigation}

Diagnosis.-This was made on clinical grounds in patients with a pattern of silvery-white striae or papules, with or without erosions, symmetrically distributed on the oral mucosa, especially on the posterior buccal mucosa. Experience has shown that clinical diagnosis of lichen planus is reliableMcCarthy and Shklar (1964)—and biopsy examination was carried out only in cases where lesions were less than typical in character, especially when only one side of the mouth was affected.

Clinical Material and Assessment of Results.-Symptoms were severe enough to require treatment in three cases. These patients were in the first instance given either hydrocortisone ( $2.5 \mathrm{mg}$.) or betamethasone $(0.1 \mathrm{mg}$.) pellets at random as part of the double-blind trial. The pellets were allowed to dissolve in the mouth, and were given four times a day. It quickly became apparent that one preparation was outstandingly effective while the other seemed ineffective except on rare occasions The effectiveness of treatment of oral lichen planus can be readily and objectively assessed by the diminution of size or disappearance of the lesions. Completely objective comparison can be made by means of serial photographs, but it is difficult to obtain an adequate and uniform angle of view. In assessing 
results, slight variations in extent of the lesion were ignored, and only complete clearance or obvious and substantial improvement was taken into account.

\section{Results}

The results of treatment of 30 patients are shown in Table I. In those cases where the condition is stated to be "cleared" after a course of treatment no visible or palpable lesion remained. This "clearing" included complete healing of erosions. "Healed" describes improvement only just short of complete clearance of oral signs-that is, healing of erosions, abolition of symptoms, but faint striae remaining visible.

\begin{tabular}{|c|c|c|c|c|c|}
\hline & BLE & & $m \in t h$ & Therapy & of Oral Lichen Planus \\
\hline $\begin{array}{l}\text { Case } \\
\text { No. }\end{array}$ & Sex & Age & Duration & Erosions & Results \\
\hline $\begin{array}{r}1 \\
2 \\
3 \\
4 \\
5 \\
6 \\
7 \\
8 \\
9 \\
10 \\
11\end{array}$ & $\begin{array}{l}\mathrm{F} \\
\mathrm{F} \\
\mathrm{M} \\
\mathrm{F} \\
\mathrm{M} \\
\mathrm{M} \\
\mathrm{F} \\
\mathrm{F} \\
\mathrm{F} \\
\mathrm{F} \\
\mathrm{M}\end{array}$ & $\begin{array}{l}69 \\
53 \\
67 \\
41 \\
56 \\
67 \\
57 \\
57 \\
43 \\
66 \\
45\end{array}$ & $\begin{array}{l}16 \text { years } \\
? 3 \text { months } \\
2 \text { years } \\
\frac{12}{12} \text { years } \\
12 \text { "” } \\
23 \text { months } \\
5 \text { years } \\
5 \text { " } \pm\end{array}$ & $\begin{array}{l} \pm \\
\pm \\
\pm \\
\pm \\
\pm \\
\pm \\
+ \\
++\end{array}$ & $\begin{array}{l}\text { Healed after } 3 \text { months } \\
\text { Healed in } 1 \text { month } \\
\text { Cleared in } 2 \text { weeks } \\
\text { Cleared in } 1 \text { month } \\
\text { Healed after } 1 \text { month } \\
\text { Clear after } 1 \text { month } \\
\text { Clear after } 1 \text { month. T } \\
\text { Did not return } \\
\text { Clear after } 2 \text { weeks } \\
\text { Healed after } 3 \text { months } \\
\text { Irregular progress. Healed after }\end{array}$ \\
\hline $\begin{array}{l}12 \\
13\end{array}$ & $\underset{F}{F}$ & $\begin{array}{l}67 \\
39\end{array}$ & $\frac{24}{?}$ & \pm & $\begin{array}{l}\text { 1 year } \\
\text { I moratter } 2 \text { months* } \\
\text { I treatment only; little }\end{array}$ \\
\hline $\begin{array}{l}14 \\
15 \\
16 \\
17 \\
18 \\
19 \\
20\end{array}$ & $\begin{array}{l}\mathrm{F} \\
\mathrm{F} \\
\mathrm{M} \\
\mathrm{F} \\
\mathrm{F} \\
\mathrm{F} \\
\mathrm{M}\end{array}$ & $\begin{array}{l}58 \\
59 \\
20 \\
62 \\
42 \\
25 \\
51\end{array}$ & $\begin{array}{l}12 \text { years } \\
? \\
? \\
6 \text { months } \\
6 \text { years } \\
3 \text { months } \\
3 \text { years }\end{array}$ & $\begin{array}{l}+ \\
\pm \\
+ \\
+ \\
+ \\
+\end{array}$ & $\begin{array}{l}\text { progress: did not return } \\
\text { Buccal lesion cleared after } 3 \text { weeks } \\
\text { Healed on hydrocortisone } \\
\text { Cleared in } 1 \text { month } \\
\text { Cleared on one side after } 3 \text { months } \\
\text { Improved }{ }^{*} \text { T } \\
\text { Healing after } 1 \text { month } \\
\text { Initial improvement. No further }\end{array}$ \\
\hline $\begin{array}{l}21 \\
22 \\
23 \\
24 \\
25\end{array}$ & $\begin{array}{l}\underset{\mathbf{M}}{\mathbf{M}} \\
\stackrel{\mathrm{F}}{\mathbf{F}} \\
\mathbf{M}\end{array}$ & $\begin{array}{l}38 \\
19 \\
66 \\
60 \\
48\end{array}$ & $\begin{array}{l}2 \text { months } \\
1 \text { year } \\
7 \text { years } \\
7 \% "\end{array}$ & $\begin{array}{l}\mp \\
\pm \\
+\end{array}$ & $\begin{array}{l}\text { progress. } \mathrm{T} \\
\text { Cleared in } 4 \text { months } \\
\text { Entirely healed in } 4 \text { months } \\
\text { Little benefit } \\
\text { Almost clear after } 1 \text { year*. T } \\
\text { Considerable improvement after }\end{array}$ \\
\hline 26 & $\mathbf{F}$ & 53 & ? & - & $\begin{array}{l}6 \text { weeks } \\
\text { Cleared after } 1 \text { month. Remained }\end{array}$ \\
\hline 27 & $\mathbf{F}$ & 50 & 6 months & - & Cleared after 2 months. Remained \\
\hline $\begin{array}{l}28 \\
29 \\
30\end{array}$ & $\underset{\mathrm{F}}{\mathrm{M}}$ & $\begin{array}{l}43 \\
22 \\
78\end{array}$ & $\begin{array}{l}5 \text { years } \\
6 \text { weeks }\end{array}$ & $\bar{E}$ & $\begin{array}{l}\text { cidear } 1 \text { year } \\
\text { Did not return } \\
\text { Clear after } 1 \text { month } \\
\text { Started to heal in } 1 \text { month; clear } \\
\text { after } 5 \frac{1}{2} \text { months }\end{array}$ \\
\hline
\end{tabular}

- Recurs when treatment is stopped. T Denotes those patients who developed thrush.

Of the 30 patients 20 showed very substantial improvement, with complete clearance of oral signs in 13; the remainder showed weak residual striae. The response was usually obvious within one month of starting treatment, and in eight cases lesions had virtually or entirely disappeared within this time. As might be expected, extensive erosions healed more slowly.

Only two patients failed to show any response after one month ; later experience suggested that more prolonged treatment might have been beneficial. One patient failed to attend again, while the remainder (five) showed progressive but gradual improvement.

Mucous Membrane Pemphigoid.-Three elderly patients with mucous membrane pemphigoid restricted to the oral mucosa were given betamethasone. In two of them the lesions cleared entirely and no sign remained. In the third patient the lesions were mainly on the gingivae in relation to severe periodontal sepsis. Nevertheless, they showed substantial improvement but had not entirely cleared after two months' treatment ; the patient then went to live in another part of the country.

Side-effects of Treatment.-The only side-effect apparent during treatment with betamethasone was that thrush developed in four patients with lichen planus and in one of the patients with mucous membrane pemphigoid.

Results of Treatment with Hydrocortisone Pellets.-From previous records only 13 patients appear to have been given hydrocortisone pellets. The results are combined with those of five other patients given hydrocortisone early in the betamethasone trial. Of these 18 patients only three showed substantial improvement in less than six months. In three cases the lesions became worse, while the remaining 12 showed no change or only gradual improvement over periods of one to three years.

\section{Natural Duration of Untreated Cases of Oral Lichen Planus}

Analysis of records of 138 patients with oral lichen planus attending this department is given in Table II. The 30 patients in the betamethasone trial are excluded. Of the 138 patients 63 attended only once, and 79 gave a history of less than a year's duration. The accuracy of the history may be doubtful in that symptoms are often absent and the lesions noticed accidentally - for example, when a visit is made to the dentist. In general, these patients had the disease in mild form.

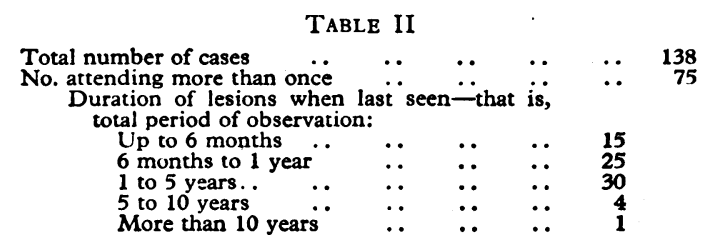

In $60(80 \%)$ of 75 patients who attended on at least one further occasion lesions were still present six months after the first visit. In 35 cases the patients attended for further observation, and lesions were still present after more than one year, and in one case after 20 years. This, however, is almost certainly an underestimate of the duration of the disease, in that patients whose lesions were not unduly troublesome failed to attend more than once or twice. The actual duration of the lesions in most cases is therefore unknown, and it is noteworthy that there is an actual record of improvement in the oral condition within six months in only three cases, irrespective of treatment. The experience in this department is therefore that oral lichen planus is often mild and of little significance, but that in the majority of cases the disease is persistent ; in most patients it is still present at least six months later, and in a few has been present for 5 to 20 years.

\section{Malignant Change in Oral Lichen Planus}

The incidence of carcinoma in oral lichen planus is not clear. Cases have been reported from time to time, but Andreasen and Pindborg (1963), in an attempt to clarify the situation by analysing previous reports, found only 46 recorded cases in over 50 years. Two of the most recent papers presenting series of cases with periods of follow-up of up to 10 years emphasize the difficulties. Thus Warin (1960) reported the cases of five patients who developed carcinoma among 53 with oral lichen planus, an incidence of $9 \%$. Altman and Perry (1961), on the other hand, found only one such case among 128 patients with oral lichen planus.

Of 138 patients with oral lichen planus seen in this department only one is known to have developed carcinoma in an area where lichen planus had been seen, but no more precise estimate of incidence can be made because of the difficulty in maintaining follow-up of the mild asymptomatic cases. There is also no certainty concerning the form of lichen planus most liable to malignant change. Andreasen and Pindborg (1963) in their analysis found that 16 of the lesions were erosive, 11 plaque-like, 5 reticular, and 14 were not specified. The interval between diagnosis of lichen planus and appearance of carcinoma also seemed to vary widely. Desbrosses (1965), reporting a single case of carcinoma in lichen planus, thought that this was 
most likely to happen with either the hypertrophic form of oral lichen planus exposed to chronic trauma or the erosive form, but provided no supporting evidence.

A factor which may be overlooked in trying to assess the incidence of carcinoma in relation to oral lichen planus is that many mild asymptomatic cases appear to be noticed only by dental surgeons, as a consequence of the close observation of the mouth essential to their work, and are referred to departments of oral medicine such as this. Dermatologists, on the other hand, are likely to see more severe or widespread cases causing symptoms, and it is from among these that most reports of malignant change have originated.

If any conclusions can be drawn it would appear that there is some association between carcinoma and oral lichen planus; but clearly there are difficulties in assessing the incidence, and estimates vary between $10 \%$ and less than $1 \%$.

While the possibility of malignant change is an important reason for treating lichen planus, the severe oral symptoms that can' be caused by uncomplicated lichen planus are enough justification for seeking an effective form of treatment.

\section{Discussion}

Williams et al. (1964) noted the " gratifying results" obtained in a small number of patients with lichen planus of the skin who used betamethasone ointment and that betamethasone was statistically superior to five other topical corticosteroids in a double-blind trial in the treatment of eczema and psoriasis.

The results of local betamethasone therapy in oral lichen planus are also most striking on both the rapidity and the completeness of the response. For quite unknown reasons only

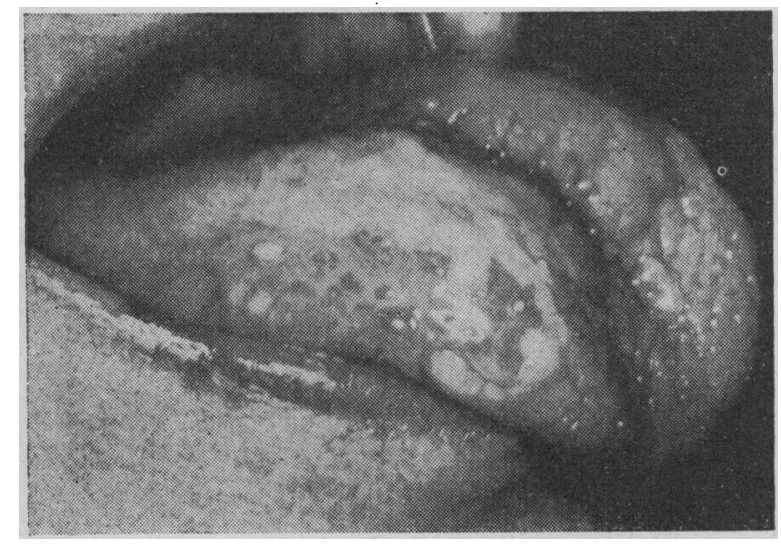

Fig. 1.-Case 30. Exceptionally severe erosive lichen planus in a woman of 78. Both sides of the tongue and cheeks were similarly affected.

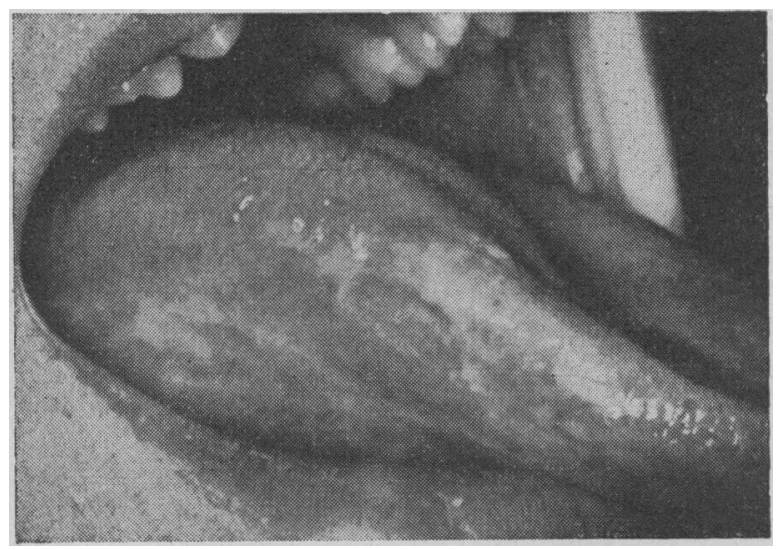

FIG. 2.-Complete disappearance of the lesion shown in Fig. 1 and of signs of lichen planus in the rest of the mouth after topical oral betamethasone therapy. Improvement was obvious a month after beginning treatment, and healing was complete after four months. a small minority of patients failed to respond ; and these failures seem to be unrelated to the duration or severity of the disease. Thus the most severe example seen (Case 30) (Figs. 1 and 2), with extensive erosions on both sides of the tongue and both cheeks, showed obvious improvement and steady progress from the start of treatment, though the exceptionally large raw areas took some five months to heal completely.

It is clear that the improvement seen in patients given betamethasone was not due to natural remission of the disease. Analysis of earlier records shows that of 75 patients $60(80 \%)$ were known to have the disorder at least six months after the first visit, and a smaller number (35) were known to have the disorder 1 to 20 years afterwards. It is also apparent that the use of hydrocortisone is rarely followed by substantial improvement within a reasonably short period of time (3 out of 18 cases).

Though only two patients with mucous membrane pemphigoid given betamethasone could be followed up, disappearance of oral signs was complete and unequivocal in both. So far neither patient has shown involvement of other mucous membranes, but should this happen and the site be inaccessible to topical therapy systemic corticosteroids would be indicated. It is obviously a great advantage if systemic therapy can be postponed as long as possible if it cannot be avoided completely.

\section{Absorption of and Adrenal Suppression by Betamethasone 17-Valerate}

The use of newer powerful corticosteroids raises doubts concerning possible systemic effects even in the minute dosage used for topical oral therapy. Friedman et al. (1967) have shown that though betamethasone caused adrenal suppression at a dosage of $8 \mathrm{mg}$. daily there was no evidence of this effect at a daily dosage of 2 to $4 \mathrm{mg}$. It seems safe to assume that : dosage of $0.4 \mathrm{mg}$. daily produces no systemic effect.

The development of thrush in a few patients using betamethasone pellets is therefore difficult to understand. Candidal infection is a recognized complication of systemic corticosteroid therapy. It is seen in those with systemic disease who are taking relatively large doses of these agents, as described by Bratlund and Holten (1954) and others. This complication is not seen in healthy patients using hydrocortisone pellets in the same way as do a great number of patients with recurrent aphthous ulceration.

In view of the absence of evidence of systemic effect from these small doses of betamethasone the development of thrush must be ascribed to local action, possibly suppression of local immunological response. This is also suggested by a case in which thrush developed in a patient with recurrent aphthae exactly in the area where betamethasone pellets were held against a persistent ulcer. It may be worth noting that in spite of the very strong suppressive effect of betamethasone on lichen planus no significant improvement was shown by it over hydrocortisone in the double-blind trial of these drugs in treating recurrent aphthae. This is perhaps surprising in view of what appears to be a strong local immunosuppressive effect of betamethasone.

\section{Conclusions}

In brief, betamethasone represents a striking advance in the management of oral lichen planus, a condition sometimes distressing, persistent, and hitherto virtually untreatable. Though a minority of patients fail to respond to betamethasone 17-valerate, the majority show an improvement often impressive in its rapidity and completeness, as did two patients with mucous membrane pemphigoid. Apart from the occasional appearance of thrush topical betamethasone caused no sideeffects. 


\section{Summary}

In 30 patients with oral lichen planus regarded as severe enough to justify treatment, use of betamethasone (Betnovate) pellets $0.1 \mathrm{mg}$. was followed by substantial improvement or complete clearance of oral lesions in 20 . Seven patients showed gradual or incomplete improvement.

Only 2 out of 30 patients failed to show any response to betamethasone, but treatment was not continued for more than one month in these cases.

Of two patients with mucous membrane pemphigoid the use of betamethasone pellets was followed by complete clearance of oral lesions. A third patient showed substantial improvement until he ceased to attend.
The only side-effect of treatment was development of thrush in four patients.

The assistance of Messrs. Glaxo in their generous supply of tablets and for other help for this trial is gratefully acknowledged.

\section{REFERENCES}

Altman, J., and Perry, H O. (1961). Arch. Derm., 84, 179. Andreasen, J. O., and Pindborg, J. J. (1963). Nord. Med., 70, 861 Bratlund, H., and Holten, C. (1954). Dan. med. Bull., 1, 79. Bratlund, H., and Holten, C. (1954), Dan. med. Bull., 1, 79.
Desbrosses, J. L. (1965). Ann. Oto-laryng. (Paris), 82, 841. Friedman, M., Fletcher, J., Hinton, J. M., Lennard-Jones, J. B. Misiewicz, J. J., and Parrish, J. A. (1967). Brit. med. F., 1, 335 McCarthy, P. L., and Shklas, G. (1964). Diseases of the Oral Mucoso. New York.

Warin, R. P. (1960). Brit. 7. Derm., 72, 288.

Williams, D. I., et al. (1964). Lancet, 1, 1177

\title{
Use of Lignocaine in Treatment of Cardiac Arrhythmias
}

\author{
F. H. N. SPRACKLEN,* M.B., CH.B., M.R.C.P. ; J. J. KIMERLING,* M.B., B.S., M.R.C.P. \\ E. M. M. BESTERMAN,* M.A., M.D., F.R.C.P.; J. W. LITCHFIELD,* B.M., F.R.c.P.
}

Brit. med. F., 1968, 1, 89-91

Since the introduction of units for intensive observation and care of patients with acute myocardial infarction arrhythmias have been found in up to $70 \%$ of such natierits (Yu et al., 1965). This finding has emphasized the lack of antiarrhythmic drugs that are generally accepted as safe to use in these circumstances, especially when parenteral therapy is necessary. In acute myocardial infarction frequent ventricular ectopic beats may require treatment as urgently as the sustained ventricular arrhvthmia that they commonly preface, especially if the ectopic beats are superimposed on the $T$ wave of the preceding electrocardiographic complex (Fig. 1). Procainamide has been widely used, but the frequency of accompanying hvpotension remains a drawback to its routine use in acute myocardial infarction.

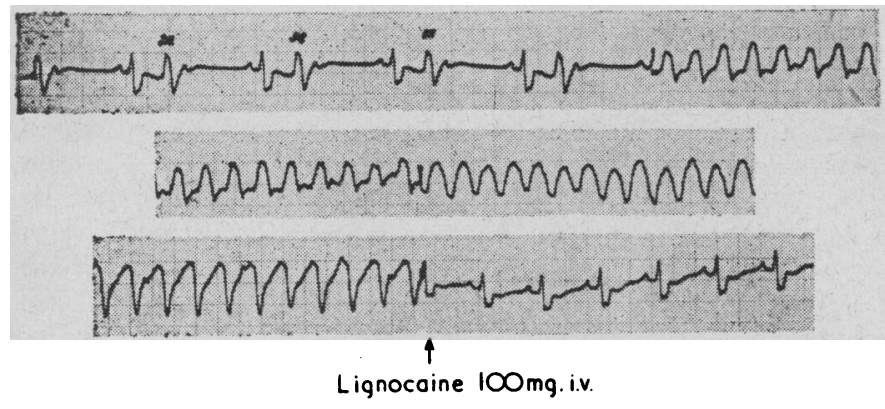

F16. 1.-Rhythm strips showing ventricular ectopic beats precipitating ventricular tachycardia ; subsequently abolished by lignocaine.

Lignocaine, which is structurally similar to procainamide, was synthesized in 1943 by Löfgren, and subsequently extensively investigated as a local anaesthetic agent (Wiedling, 1964). Southworth et al. (1950) reported the successful use of lignocaine in association with alternating-current shock in a case of ventricular fibrillation arising during cardiac catheterization. Subsequent authors have confirmed the value of lignocaine in abolishing or preventing ventricular arrhythmias in animals under a variety of experimental conditions (Van Dongen, 1953 ; Melon et al., 1953 ; Visentini, 1954 ; Frederickson and Morris, 1955 ; Cahn, 1955; Carden and Steinhaus, 1956; Harris

- Department of Cardiology, St. Mary's Hospital, London W.2. et al., 1956 ; Hitchcock and Keown, 1958 ; Austen and Moran, 1965). Greenspan et al. (1966) have shown lignocaine to be more effective than quinidine in restoring sinus rhythm in dogs with digitalis-induced ventricular arrhythmias ; Katz and Zitnik (1966) have similarly shown the superiority of lignocaine over direct-current shock in these circumstances.

In a large series of over 500 cases Hitcheock and Keown (1959) have shown the efficacy of lignocaine in the management of cardiac arrhythmias during cardiac surgery in man. This work has been confirmed by Weiss (1960). Likoff (1959) successfully used lignocaine for the control of various arrhythmias arising during surgery. De Sanctis (1965), Minuck (1965), and Bedynek et al. (1966) reported the use of lignocaine in the treatment of ventricular ectopic beats and ventricular tachycardia of non-surgical origin. It therefore appeared to be a drug worthy of further evaluation. This report is based on experience over the past year in a coronary intensive care unit, a cardiac surgical recovery ward, and the general medical wards.

\section{Material and Methods}

Fifty-five patients were treated with lignocaine for a variety of arrhythmias. The drug was usually given intravenously, though some patients received it by intramuscular injection. Initially 1-2 mg. of lignocaine per $\mathrm{kg}$. body weight was used, repeated, if necessary, every 20 minutes to a maximum of 500 mg. Subsequently it was found more satisfactory to use a "loading" dose of 1-2 mg. $/ \mathrm{kg}$. followed by the slow infusion of 1-2 mg./minute in a drip. For this purpose $500 \mathrm{mg}$. of lignocaine was added to $500 \mathrm{ml}$. of $5 \%$ dextrose in water; it was then infused at 10 to 20 drops a minute, according to the patient's response, and continued for up to 48 hours. Five hundred units of heparin was added to prevent the thrombophlebitis that commonly accompanied prolonged infusion of lignocaine into one vein.

Cardiac outputs were determined in three patients before and 10 minutes after recelving $2 \mathrm{mg}$. of lignocaine per $\mathrm{kg}$. intravenously. One had a normal heart, one a small left ventricular aneurysm, and the third a cardiomyopathy. Pulmonary artery and brachial artery pressures were recorded, and cardiac out- 